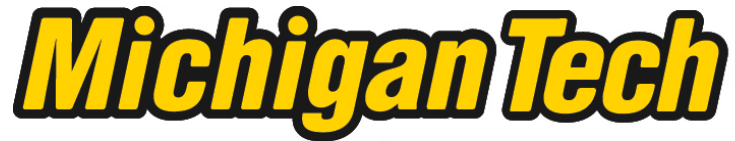 \\ Michigan Technological University Create the Future Digital Commons @ Michigan Tech
}

Dissertations, Master's Theses and Master's Reports - Open

Dissertations, Master's Theses and Master's

Reports

2014

\section{MICHIGAN TEACHER EXCELLENCE PROGRAM: PERSONAL EXPERIENCES AND IMPACT}

Rebecca A. Joyce

Michigan Technological University

Follow this and additional works at: https://digitalcommons.mtu.edu/etds

Part of the Science and Mathematics Education Commons

Copyright 2014 Rebecca A. Joyce

\section{Recommended Citation}

Joyce, Rebecca A., "MICHIGAN TEACHER EXCELLENCE PROGRAM: PERSONAL EXPERIENCES AND

IMPACT", Master's report, Michigan Technological University, 2014.

https://doi.org/10.37099/mtu.dc.etds/881

Follow this and additional works at: https://digitalcommons.mtu.edu/etds

8 Part of the Science and Mathematics Education Commons 


\title{
MICHIGAN TEACHER EXCELLENCE PROGRAM: PERSONAL EXPERIENCES AND IMPACT
}

\author{
By \\ Rebecca A. Joyce \\ A REPORT \\ Submitted in partial fulfillment of the requirements for the degree of \\ MASTER OF SCIENCE \\ In Applied Science Education \\ MICHIGAN TECHNOLOGICAL UNIVERSITY \\ 2014 \\ (C) 2014 Rebecca A. Joyce
}


This report has been approved in partial fulfillment of the requirements for the Degree of MASTER OF SCIENCE in Applied Science Education.

Department of Cognitive and Learning Sciences

$\begin{array}{cl}\text { Report Advisor: } & \text { Bradley Baltensperger } \\ \text { Committee Member: } & \text { Kedmon Hungwe } \\ \text { Committee Member: } & \text { Chris Wojick }\end{array}$

Department Chair: Susan L. Amato-Henderson 


\begin{abstract}
This report is a summary of the effects of the Michigan Teacher Excellence Program (MITEP) on me as a science educator. The first chapter is a report of an action research project jointly authored with two other science teachers participating in the MITEP program titled "Station Activities and Misconceptions in the Chemistry Classroom." The second chapter is a reflective essay evaluating the impacts of the MITEP experience on my teaching skills and practice, knowledge of science education and science education research, and leadership skills. The most significant impacts were a dramatic increase in my earth science content knowledge, a deeper understanding of inquiry-based teaching methods, and an expanded professional network of science educators.
\end{abstract}




\title{
Chapter 1
}

\section{Action Research: Station Activities and Misconceptions \\ in the Chemistry Classroom}

By Claudia Witt, Kari Luckett, Rebecca Joyce

\begin{abstract}
Motivation for the study
This action research was conducted by a group of three science teachers who have worked together as part of the Michigan Teacher Excellence Program (MITEP). The MITEP program was designed to develop teacher leaders who are empowered to “...lead their schools and districts through the process of systematically improving science teaching and learning." (Michigan Teacher Excellence) Though we each work in different high schools we have participated in this professional development program together for two years and share an interest in science education that is focused and effective for our students.
\end{abstract}

As part of our participation in MITEP, and in the Michigan Technological University Action Research course taught by Kedmon Hungwe, we collaborated on the design, implementation and reporting of an action research project. Our roles in the research reflect our current teaching roles. Claudia Witt has been teaching chemistry for six years at Loy Norrix High School in Kalamazoo Public Schools (KPS). Kari Luckett 
has been teaching chemistry at Kalamazoo Central High School in KPS for eight years. Rebecca Joyce works at the Kalamazoo Area Mathematics and Science Center, a countywide program which supports math and science education. In the past she has taught high school physical science, earth science and elementary science. She currently works with high school students on college and career preparation. Claudia and Kari reflected on topics relevant to their needs in the classes they have in common. Rebecca, Claudia and Kari discussed the rationale for the research and decided on the research question. Rebecca researched publications addressing common misconceptions in chemistry and shared her summaries with Kari and Claudia as they planned their research design. In their respective classrooms, Claudia and Kari administered the learning stations, observed students, collected data, analyzed the misconceptions and chose samples of student work. Rebecca visited two of Claudia's classes to watch students working at learning stations and record observations. They worked together to draft and edit the report. Rebecca focused on the readings section, Claudia and Kari focused on descriptions of their classes and curricula, and together they discussed the analysis, interpretation and conclusions.

Kalamazoo Public Schools has two regular high schools and one alternative high school. Loy Norrix High School has 1514 students, 44\% of whom are white, 37\% African American, and 14\% Hispanic. Kalamazoo Central has approximately 1620 students, of whom $48 \%$ are African American, $34 \%$ are white, and $8 \%$ are Hispanic. At Loy Norrix $66 \%$ of students qualify for free and reduced lunch and at Kalamazoo Central $63 \%$ of students qualify for free and reduced lunch. 
Secondary schools in KPS have recently switched from a block schedule to trimesters, so what was once a one semester class of chemistry has been switched to a two trimester Chemistry A and Chemistry B class. A passing grade in Chemistry A is a prerequisite to be enrolled in Chemistry B. In Michigan, students must take either Chemistry or Physics to graduate (for KPS Chemistry A and Chemistry B or Physics A and Physics B). Most students choose to take Chemistry A and Chemistry B as there is a reputation for it being an easier, less math-intensive class. Claudia is part of one of the Sophomore Academy teams at Loy Norrix and most of her students are in $10^{\text {th }}$ grade, although her students range from $10^{\text {th }}$ to $12^{\text {th }}$ grade. Kari is part of a liberal arts and international studies SLC, small learning community. The students in this SLC range from $10^{\text {th }}$ to $12^{\text {th }}$ grade. Based on her schedule, Kari primarily teaches outside of her SLC, having mainly 10th graders from the health and science and engineering small learning communities. There is no reading requirement for Chemistry in KPS, so readers of all abilities and levels can be enrolled. Students must pass both Biology A and B in order to enroll in Chemistry (or Physics). In addition, students must pass a minimum of Algebra in order to be eligible for Chemistry. As Chemistry/Physics is a graduation requirement, students who have previously been unsuccessful are re-enrolled in the class. Generally there are less than five "repeater" students in a given chemistry class. In KPS, we also give students the option of taking Honors Chemistry instead of General Chemistry. Honors Chemistry has a different curriculum, which covers the same content as General Chemistry, in addition to more complicated topics. KPS also offers sections of co-taught Chemistry, where a content teacher and a special education teacher teach together. These 
classes typically have between five and fifteen special education students in each class period. These students have a range of disabilities and receive services to have content modified and differentiated. At Kalamazoo Central, Kari teaches all of the co-taught chemistry classes.

In chemistry, many of the concepts require consistent and regular practice for students to master the concept. In co-taught classes, students were getting bogged down or overwhelmed by long and numerous worksheets. Also it was hard to see where students were developing misconceptions because the grading of many worksheets was cumbersome on the teacher. We wanted to find a way to practice the concepts in a segmented fashion, where students could address concepts in a small amount of time and with a limited number of questions and teachers could address small groups and look for/address misconceptions that had developed.

In both Claudia and Kari's Chemistry classes, all students are required to take a pretest at the beginning of the course. In addition, Claudia gives a five-question pretest at the beginning of each chapter. The questions chosen on the chapter pretest generally include broad topics to be covered within the chapter. Students are required to complete the pretests, and are given a formal grade on them which does not affect their overall class grade. The pretest grades are calculated with a weight of zero and are hidden in the online grade book so students and parents cannot see them. Comparing the class and chapter pretests to post tests in both situations help demonstrate student growth. Through the collaboration of Claudia and Kari, Claudia has started using station activities in her 
Chemistry classes. The hope is that with additional practice, more students show more success on their post tests (both chapter and final exam). The topic we chose to research dealt with the theory behind atomic structure. We picked this topic because our research was happening during the fall trimester and we had common content with Chemistry A during that time. We wanted to give ourselves enough time to research and analyze our findings, so we determined the theory of atomic structure to be the ideal unit.

Claudia and Kari use daily warm ups which usually consist of a question for which there is a correct answer. After determining misconceptions using the pretests, they give a lecture with slides on the concept. Warm ups are used on subsequent days to help students review and explain in their own words corrections to these misconceptions. Warm ups are graded and returned to students on a daily basis. This year, stations have also been introduced to Claudia's classroom through collaboration with Kari, who uses them on a regular basis. During the stations activities, common misconceptions are addressed again and written about by the students. Students are invited to use notes, worksheets, books, warm ups, etc. during the stations activities, however they are encouraged to attempt to complete the activity without them to help them gauge their progress in a particular unit. Station activities are typically done the day prior to a test. To determine if the misconceptions were properly addressed and practiced, students were again assessed on their chapter test.

Since Kari and Claudia already have previous experience in using rotating learning stations and have found them worth continuing, we wanted to know more about 
this method and its effectiveness. We wanted to observe students more closely and gather data on their work in stations. We wanted to see if students stayed on task during station time and were able to complete the assignments at each station independently.

We also wanted to use the stations to address student misconceptions in chemistry. We often hear our students voice misconceptions when we elicit prior knowledge at the beginning of a unit. These conceptions can be difficult to change. We wanted to identify misconceptions students held in this unit, identify which students had these misconceptions, and help them develop their understanding. We hoped that we could more easily identify their misconceptions by observing students during the time they worked at stations and discussed station tasks with their peers. Other science teachers may be interested in the results of our study because the misconceptions we are investigating are common and may impact student understanding of chemistry, physics and biology.

\section{Research question}

The research question we chose was "What will happen if we try to use station activities to address student misconceptions in atomic structure?" Initially we planned to study the question "How will the use of station activities affect student misconceptions in the atomic structure unit?" However, when we planned our data collection design we decided "What will happen if we try to use station activities to address student misconceptions in atomic structure?" would be a more appropriate question because we 
were looking more generally at both teacher and student learning. We made this adjustment because we thought to answer the first question thoroughly and conclude that the intervention of station activities affected student misconceptions we would need pre and post tests and a control group. We were not able to do that in this time period but it would be a good second stage for this action research.

\section{Readings about the study}

In our readings the terms "misconceptions," "pre-conceptions," and "student alternative conceptions" were used to describe ideas that were not in accord with current science. There is some controversy over these terms but we chose to use the term "misconception," judgmental as it is, because it reflects how these ideas are approached in our teaching practice. In an era of high-stakes standardized testing we are motivated to teach students the "correct" and standard scientific explanations as quickly as possible.

We do, however, know that it is important for us to develop as much understanding as possible about what these misconceptions are. As Horton states, "Learning is an active process, and what students do with facts and ideas with which they have been presented depends to a very high degree on what they already think and believe. Being able to recognize and work with these student-held ideas and conceptions is thus a key component of an effective educational strategy." (Horton, 2004) 
In some cases, the misconceptions are deeply rooted and make it hard for students to assimilate new information. Mulford and Robinson (2002) also address this problem, stating:

Alternative conceptions play a larger role in learning chemistry than simply producing inadequate explanations to questions. Students either consciously or subconsciously construct their concepts as explanations for the behavior, properties or theories they experience. They believe most of these explanations are correct because these explanations make sense in terms of their understanding of the behavior of the world around them. Consequently if students encounter new information that contradicts their alternative conceptions it may be difficult for them to accept the new information because it seems wrong...If anomalous new information is presented in a learning situation where the student is rewarded (with grades) for remembering it, the information may be memorized in order to earn the reward, but it is likely to be quickly forgotten because it does not make sense.

In our reading, we looked for specific misconceptions that our students might hold in the atomic theory or following units. The University of Dallas's Comprehensive Conceptual Curriculum for Physics describes the following misconceptions which students may have in atomic structure:

There is only one correct model of the atom.

Electrons in an atom orbit nuclei like planets orbit the sun. 
Electron clouds are pictures of orbits.

Electrons can be in any orbit they wish.

Hydrogen is a typical atom.

The wave function describes the trajectory of an electron.

Electrons are physically larger than protons.

Electrons and protons are the only fundamental particles.

Physicists currently have the "right" model of the atom.

Atoms can disappear (decay) (Olenick)

In addition, a common error that students make is “...the easily avoidable one of not counting the correct number of electrons (equal to the atomic number for a neutral atom). They also fail to take into account the loss or gain of electrons if the subject species is an ion" (Miller). Other common misconceptions we identified in our reading were "Atoms are like cells with a membrane and nucleus, "The size of an atom depends on the number of protons it has," and "Hydrogen is a typical atom" (Horton, 2004).

\section{Research plan for the study}

This study was conducted at Kalamazoo Central High School and Loy Norrix High School in Kalamazoo, Michigan. The courses investigated were Chemistry and Honors Chemistry with students in grades 10-12. We read articles on the topics of common misconceptions in chemistry and identified common misconceptions about 
atomic structure. We did not find literature about the use of learning stations in high school science classrooms. The use of learning stations in elementary classrooms appears to be more common.

We designed the learning station activities so that three of the stations would identify students who have these common misconceptions. At the stations, we planned to assess whether students have these misconceptions by observing them completing activities and through their writing at stations. We planned to set up between four and eight stations throughout the classroom. Students would receive a station guide and would have about have about ten minutes at each station to complete the activity. Teachers would address any misconceptions observed by immediately by talking to students at a station.. We collected samples of students' warm up questions, station guides, quizzes and chapter tests including items assessing those specific misconceptions we observed. Examples of these test items can be viewed in the following section.

\section{Analysis and Interpretation}

In our reading we identified several common misconceptions that were relevant to our teaching in this unit. Of those common misconceptions in the literature, we noticed some overlap with misconceptions we observed in our classes. The chart below notes student misconceptions we noted in the classes as well as how they were identified and addressed. These misconceptions primarily consist of chapter four content surrounding atomic theory and the scientists who contributed to it. 


\begin{tabular}{|c|c|c|c|c|}
\hline $\begin{array}{l}\text { Source } \\
\text { Chapter }\end{array}$ & Misconceptions & $\begin{array}{l}\text { How it was } \\
\text { identified }\end{array}$ & $\begin{array}{l}\text { Teacher follow up to address } \\
\text { misconception }\end{array}$ & $\begin{array}{l}\text { How } \\
\text { students } \\
\text { were } \\
\text { assessed }\end{array}$ \\
\hline Chapter 2 & $\begin{array}{l}\text { Dissolve is a Chemical } \\
\text { Change }\end{array}$ & $\begin{array}{l}\text { Noticed } \\
\text { during an } \\
\text { activity }\end{array}$ & $\begin{array}{l}\text { Immediate feedback during } \\
\text { stations } \\
\text { PowerPoint slide with correct } \\
\text { definition in lecture } \\
\text { John Collins writing prompt }\end{array}$ & $\begin{array}{l}\text { Question } \\
\text { and \% of } \\
\text { Students } \\
\text { Correct }\end{array}$ \\
\hline Chapter 4 & $\begin{array}{l}\text { "JJ Thomson's contribution } \\
\text { was the Plum Pudding } \\
\text { Model" }\end{array}$ & $\begin{array}{l}\text { Warm Up - } \\
\text { John Collins } \\
\text { Type } 2 \\
\text { writing }\end{array}$ & $\begin{array}{l}\text { Discussed in following classes } \\
\text { and next day in first class }\end{array}$ & $\begin{array}{l}\text { Essay } \\
\text { question } \\
\text { on } \\
\text { Chapter } \\
4 \text { Test }\end{array}$ \\
\hline $\begin{array}{l}\text { Chapter } 4 \\
(10 / 3 / 13)\end{array}$ & $\begin{array}{l}\text { "Atomic Mass" as a part of } \\
\text { the chart }\end{array}$ & $\begin{array}{l}\text { Overheard } \\
\text { students } \\
\text { discussing it }\end{array}$ & $\begin{array}{l}\text { Announced to class that there is } \\
\text { no such thing as "atomic mass" } \\
\text { at this point. It's atomic } \\
\text { number and mass number }\end{array}$ & $\begin{array}{l}\text { Chapter } \\
4 \text { Test - } \\
\text { Chart on } \\
\text { first page }\end{array}$ \\
\hline $\begin{array}{l}\text { Chapter } 4 \\
(10 / 8 / 13)\end{array}$ & $\begin{array}{l}\text { Rutherford's contribution } \\
\text { was the gold-foil experiment } \\
\text { and he discovered the } \\
\text { nucleus... (missing the HOW } \\
\text { part, need more information) }\end{array}$ & $\begin{array}{l}\text { Warm Up-- } \\
\text { John Collins } \\
\text { type } 2 \text { writing }\end{array}$ & $\begin{array}{l}\text { Discussed in following class } \\
\text { and next day in first class }\end{array}$ & $\begin{array}{l}\text { Essay } \\
\text { question } \\
\text { on } \\
\text { Chapter } \\
4 \text { Test }\end{array}$ \\
\hline Chapter 4 & $\begin{array}{l}\text { Rutherford only discovered } \\
\text { the nucleus }\end{array}$ & $\begin{array}{l}\text { Warm Up - } \\
\text { John Collins } \\
\text { type } 2 \text { writing }\end{array}$ & $\begin{array}{l}\text { Discussed in following class } \\
\text { and next day in first class }\end{array}$ & Test \\
\hline Chapter 4 & $\begin{array}{l}\text { Neutrons make atoms } \\
\text { electrically neutral }\end{array}$ & $\begin{array}{l}\text { Practice } \\
\text { worksheet }\end{array}$ & $\begin{array}{l}\text { Discuss in notes, warm ups, on } \\
\text { quiz, on essay question on test }\end{array}$ & $\begin{array}{l}\text { Quiz and } \\
\text { test essay } \\
\text { question }\end{array}$ \\
\hline Chapter 4 & $\begin{array}{l}\text { There is only one model of } \\
\text { an atom (usually Bohr } \\
\text { model) }\end{array}$ & $\begin{array}{l}\text { Observation, } \\
\text { during lecture }\end{array}$ & $\begin{array}{l}\text { PowerPoint to address more } \\
\text { current models of the atom }\end{array}$ & $\begin{array}{l}\text { Warm } \\
\text { Up }\end{array}$ \\
\hline
\end{tabular}


We focused on two particular misconceptions through the methods listed in the chart. Multiple students in both schools held misconceptions about the contributions of Ernest Rutherford and J.J. Thomson to atomic structure. We wanted students to understand on a basic level the relationship between these scientists' investigations and their conclusions about the atom: that Rutherford concluded that the atom contained a positively charged nucleus and was mostly empty space and that Thomson discovered the electron using the cathode ray tube and developed the plum pudding model of the atom. We first examined students" prior knowledge with the pretest prompts "Explain J.J. Thomson's model of the atom" and "Explain Rutherford's model of the atom". Below is a sampling of student responses.

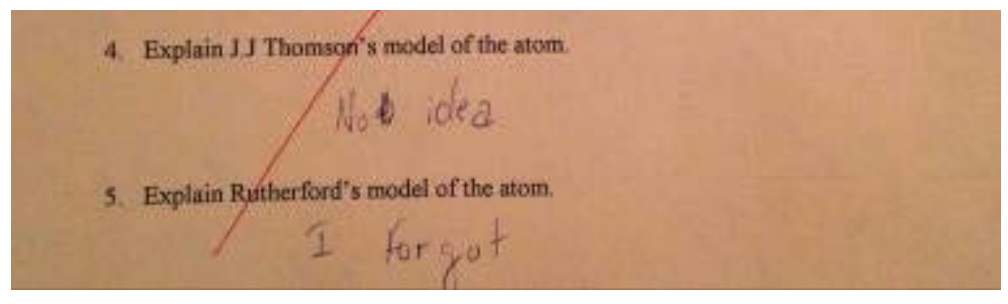

Image 1 - student pretest: student did not know any of the answers.

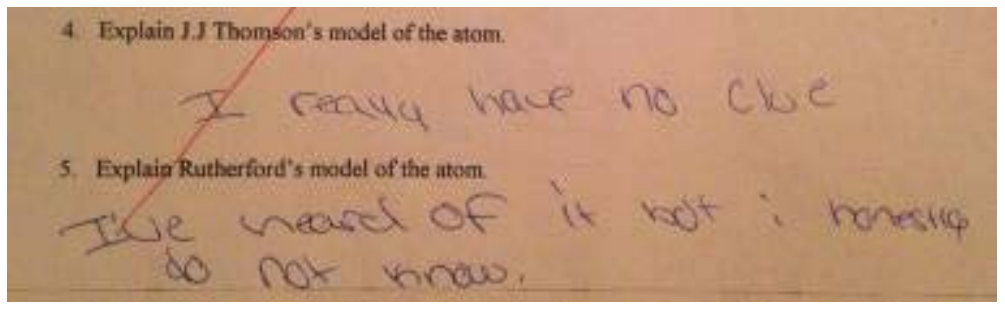

Image 2 - student pretest: student did not know any of the answers but said they have heard of Rutherford's model. 
After the pretest, the scientists' contributions to the corresponding atomic models were taught through direct instruction with PowerPoint slide images, student notes taken from the textbook, small group research summarized in a poster, and peer presentations of the posters. After these activities, students were given a warm up question on a subsequent day using the same prompts from the pretests to determine their understanding.

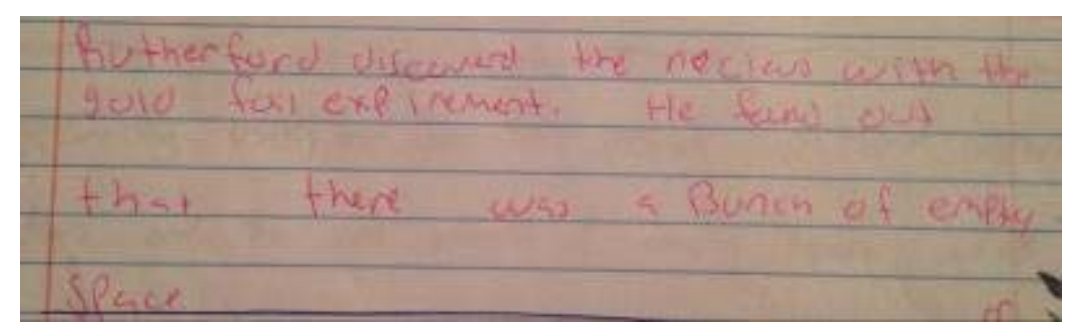

Image 3 - student warm up: This student was missing the "how" part of Rutherford's contribution. He/she also didn't describe the experiment.

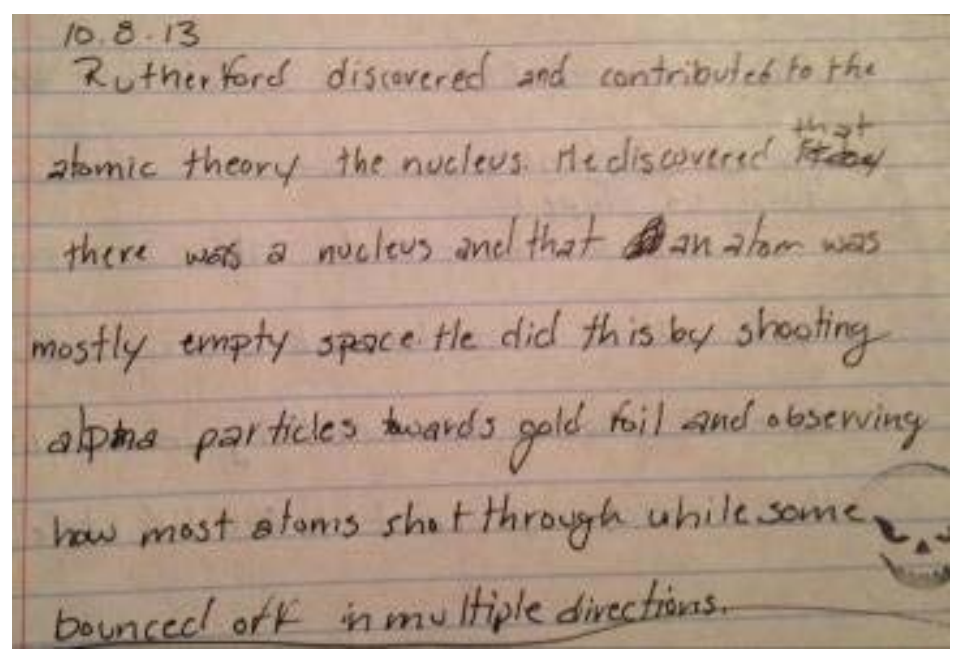

Image 4 - student warm up: This student had a great grasp of Rutherford's contribution to the atomic theory and included all of the components we were looking for in this prompt. 


\section{more on test.}

Image 5 - student warm up: This student understood the basics of Rutherford's model ("He discovered the nucleus"), however was missing the key components of the "how" and the concept of empty space.

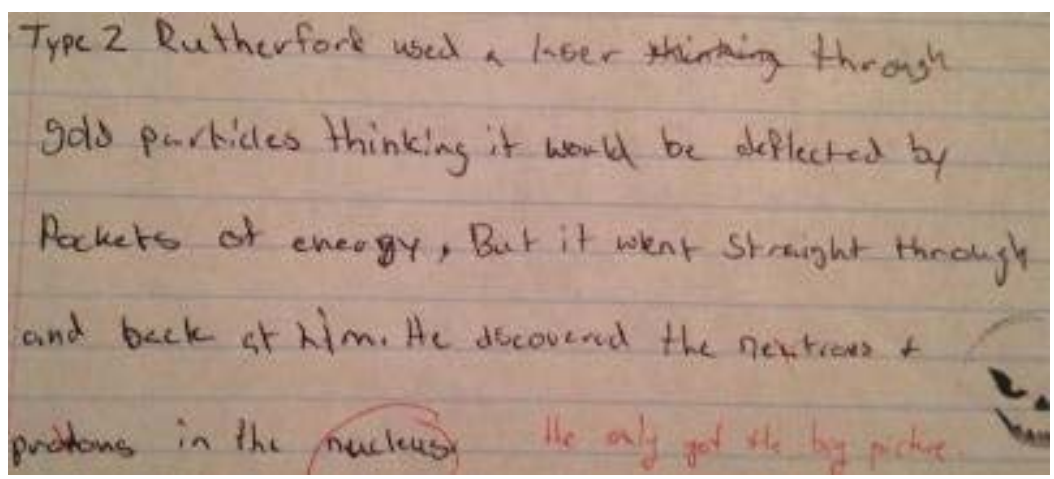

Image 6 - student warm up: Student was missing some details about empty space and added some incorrect information about Rutherford's discovery.

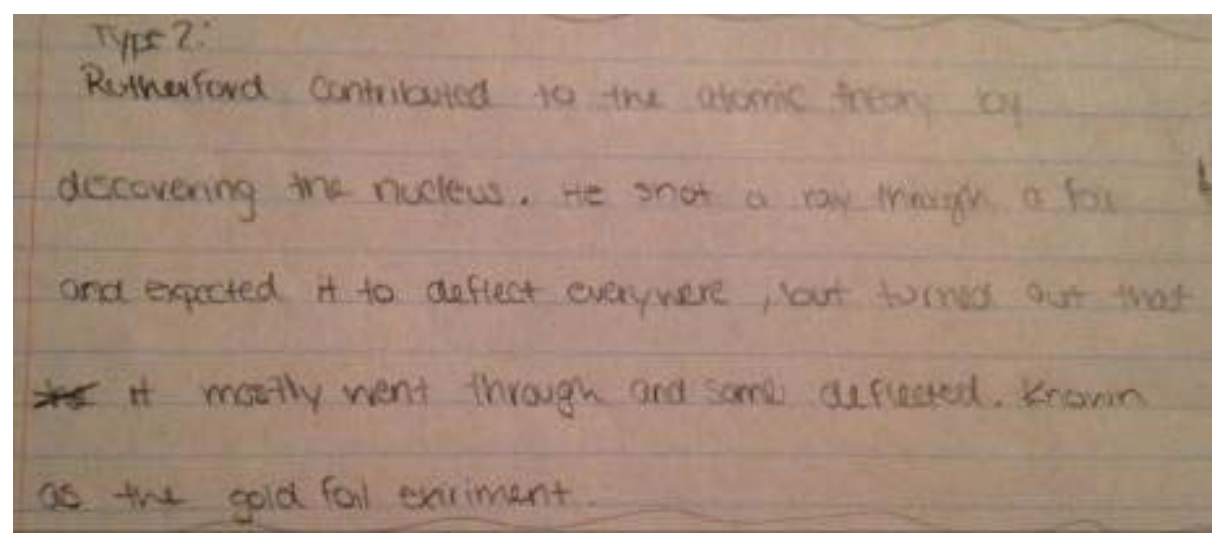

Image 7 - student warm up: Student was missing the idea that Rutherford contributed to the idea that atoms are mostly empty space.

As a final review before the unit assessment, students performed the stations activity. We wanted to see if the interventions and practice we had provided changed or strengthened students' understanding of atomic models. For consistency, the questions 
were phrased the same way: "Explain J.J. Thomson's model of the atom" and "Explain Rutherford's model of the atom".

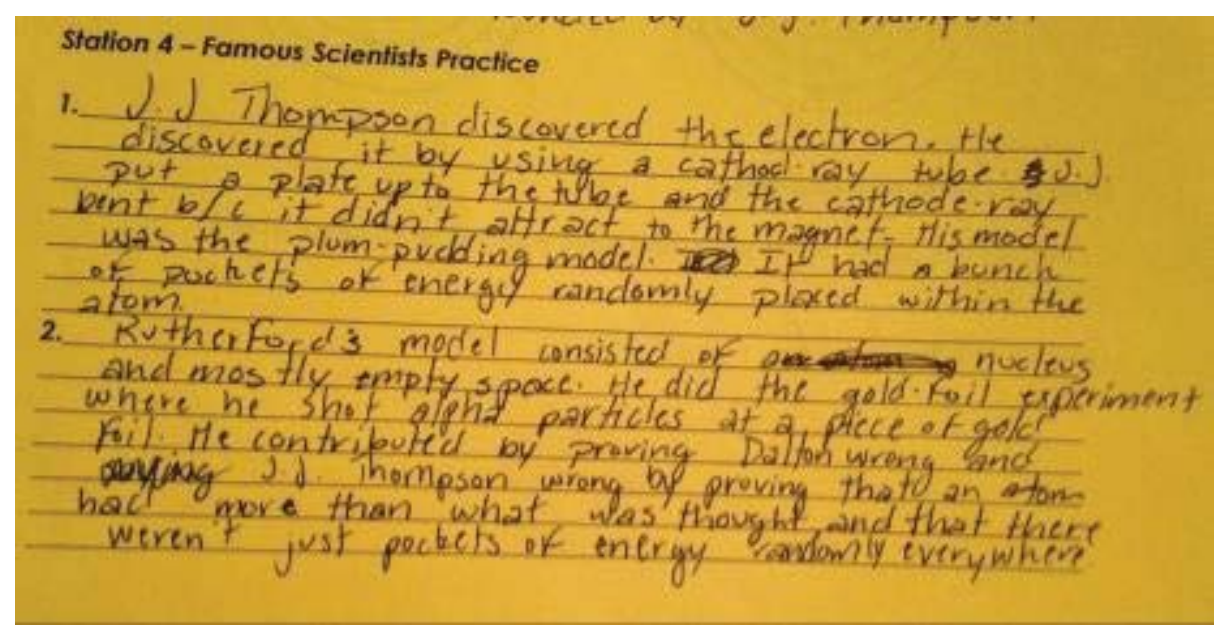

Image 8 - student station guide: thorough answers made for both questions by student.

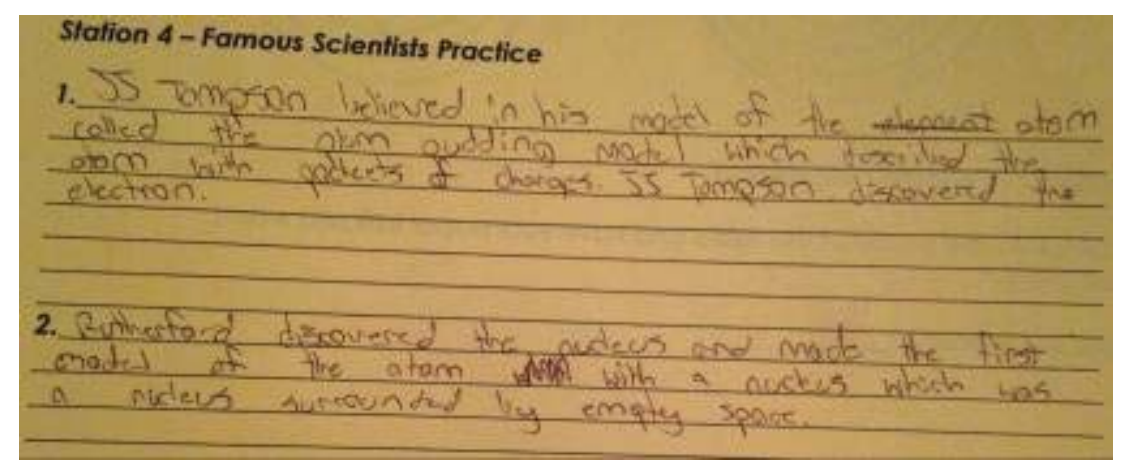

Image 9 - student station guide: student did not describe how both J.J. Thomson and Rutherford made their discoveries. 


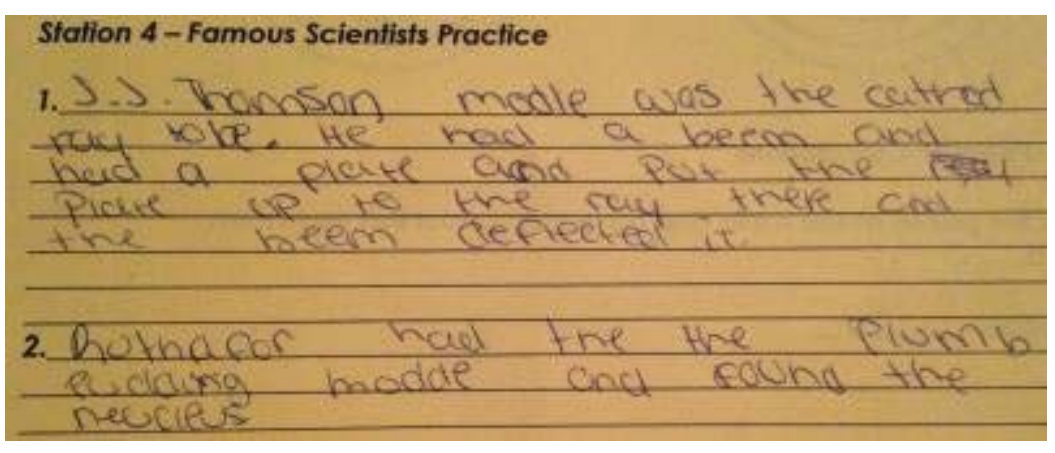

Image 10 - student station guide: student described Thomson's experiment, but failed to mention what he actually discovered. Student stated that Rutherford had the plum pudding model and lacked details about Rutherford's experiment or model.

Another persistent misconception that we noticed was not addressed in the stations activity but was taught using other strategies. This misconception is that an atom is electrically neutral because of neutrons (arising because the words are similar). This concept was taught first in a lecture. The students learned that in a neutral atom the number of electrons is equal to the number of protons; therefore the negative charges cancel out the positive charges. The concept was revisited several times in an inquiry activity, an atoms practice sheet, and a quiz before the students took the unit assessment. Below are samples of student work which show a range of answers on the atoms practice sheet and the atoms quiz. 


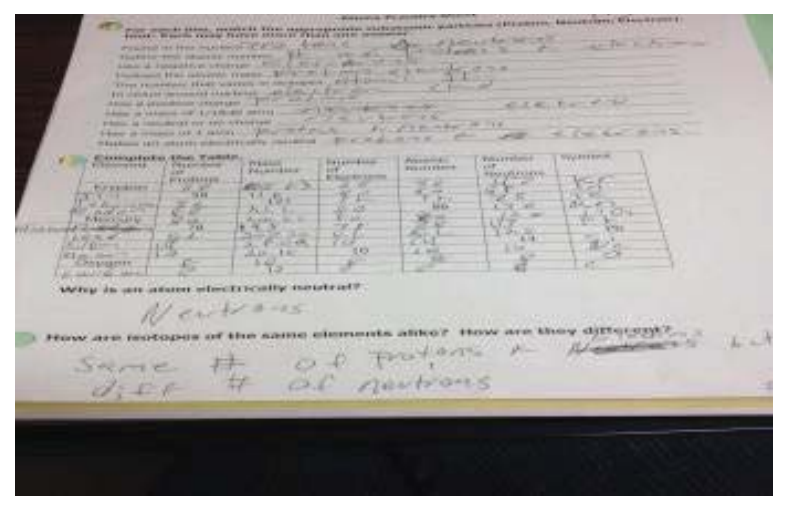

Image 11: student incorrectly answered the question "Why is an atom electrically neutral?" with "Neutrons" on the atoms practice sheet.

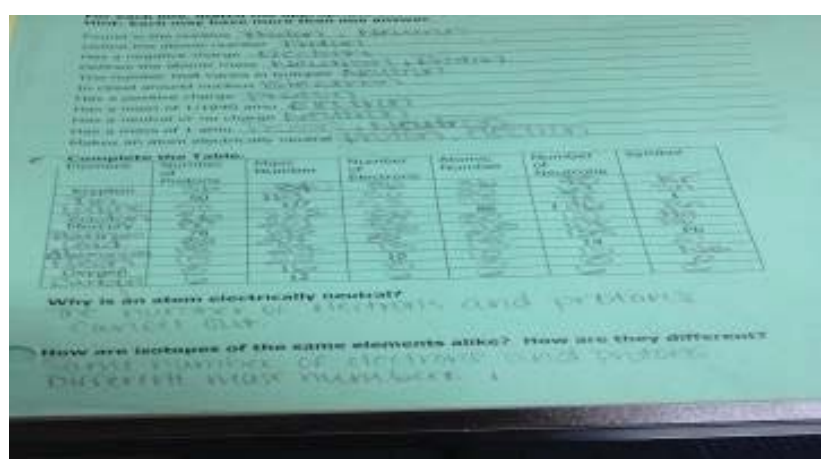

Image 12: student correctly identified question "Why is an atom electrically neutral?" on the practice sheet with "The number of electrons and protons cancel out."

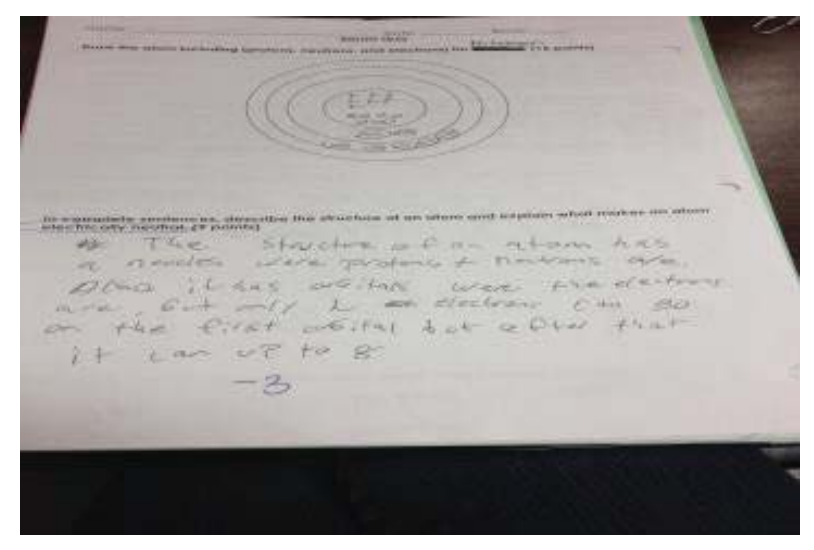

Image 13: for the quiz question "Describe the structure of an atom and explain why an atom is electrically neutral" student only describes the structure and omits describing why it is electrically neutral. 


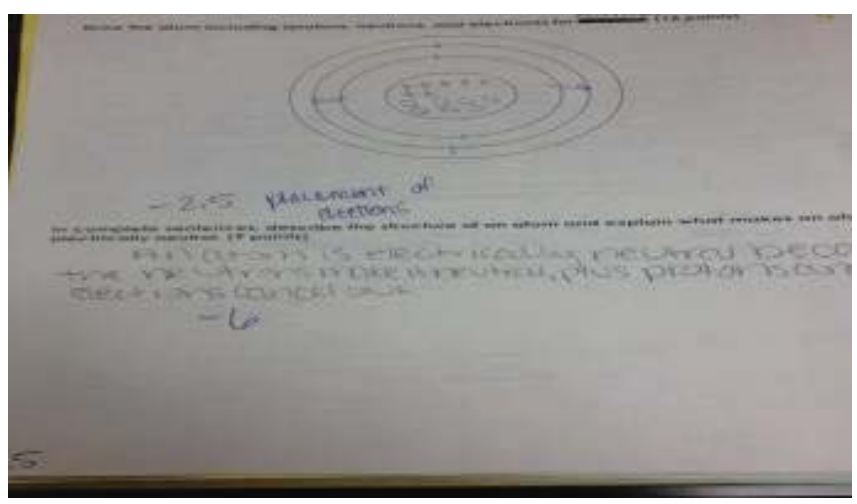

Image 14: student incorrectly answers "An atom is electrically neutral because the neutrons make it neutral, plus protons and electrons cancel out" on the quiz.

\section{Discussion}

Elementary classrooms often use stations, or centers, as an effective learning strategy and we were also able to see success with this strategy in our secondary classrooms. We observed that stations provided an opportunity to meet diverse student needs in several ways. For one, they provided all students an opportunity to get more individualized support because the teachers circulated among the stations. One teacher was able to listen to, discuss, and re-teach a group of three to four students on a chunk of content that was previously taught. We observed more student discussion because students were standing together at the same station instead of at their individual desks. Also, the stations provided a visual and often hands-on activity to help strengthen understanding. Additionally, the activity provided an alternative to a worksheet, where the student's focus was on practicing one key concept, with fewer questions and lots of teacher support. In the stations format we were able to check-in with our special education students without singling them out in a whole-group setting. 
Kari and Claudia have often used stations to go beyond the initial lecture and practice, in order to further the students' understanding and review for assessments. They have used matching models, Venn diagrams, computer animations, and other manipulatives in particular stations. Kari found that matching models allowed students to quickly categorize content. This type of station allowed her to quickly assess student understanding and what needed to be re-taught. Also, these stations forced students to get their work checked and initialed by the teacher, providing an opportunity for Kari to collect informal data and re-teach on the spot. Claudia found that the use of stations as a review activity has increased time on task for her students. Kids who usually would wait to do a worksheet or other review work at home or choose not to complete it at all, were required to get the work done in class. This allowed Claudia to make observations and determine which topics needed more time and practice in the future. Additionally, students who would normally have incomplete or missing work were completing the work in class. Claudia was also able to address students' misconceptions or incorrect answers immediately to steer them in the right direction for the future assessment. For teachers it provided a quick informal check on student understanding. While we might not be able to tell if the student conceptions have changed because of that station activity, we can see if they are learning or strengthening their understanding.

In student evaluations, we found the students sometimes disliked the idea of stations (primarily because we force them to get up and move around) but also stated that stations were instrumental in developing understandings in each unit of study. Students 
report that they like the student-to-teacher ratio during stations, where the teacher is circulating and readily available to provide support.

Kalamazoo Public Schools requires the use of common growth assessments as part of annual teacher evaluations. By using several different learning strategies and formative assessments, including stations, we were able to use the observational data we collected as part of our evaluation. In our opinion, data from district level assessments alone was not reflective of what occurred in our classrooms. As teachers, we are allowed to provide additional evidence of student learning, when or if the district data is not reflective of the required student improvement. The data we collected helped support our teaching methodologies and effectiveness.

Through this study we made many observations about the utility of stations as a strategy in our classrooms, but did not determine whether the stations led to conceptual change for students who came into the unit with incorrect preconceptions or developed misconceptions during the unit. As we collected data we did not link it to individual students so we did not know which students had misconceptions and if they were corrected through the use of stations, through the use of other strategies, or not corrected.

\section{Conclusion}

In this study we learned about student misconceptions in atomic theory and structure in the literature and in our classes. Our list of misconceptions in this unit was 
different from the ones present in the literature because we focused only on atomic structure and asked specifically about theorists and their contributions. Our students shared a misconception identified in our readings as common: "there is only one correct model of the atom."

We also determined that more research needs to be done to conclusively determine if the misconceptions were corrected during stations activities. The pretest format we used could work well, but specific questions would need to be modified in order to make the connection between the pre and post test data. Many students know that the pretest is not connected with a grade, therefore do not take them seriously. Most students put their name on it and turn it in completely blank or randomly answer questions. This could skew our results greatly.

The structure of the stations allowed us to easily assess the students' understanding, but because of the teacher to student ratio (both Kari and Claudia had over 25 students in each class), we couldn't assess and address every student at every station. Other teachers might find it useful to integrate stations into their classrooms because it is a great alternative to worksheets. It addresses the kinesthetic learning style and encourages student movement and discussion during class. It allows teachers to circulate so students can have one on one interaction when possible. It is especially beneficial in co-taught classes where there is more than one adult in the room. It reduces the number of questions that a student needs to complete and gives them a concrete time frame for each station. The ability to move on after a given time frame regardless of station 
completion is acceptable as long as the student is engaged at each station. For teachers, this is an easy way to modify and differentiate the activity for learners with different ability levels.

All teachers could also benefit from being aware of their students' common misconceptions. Knowing these misconceptions give teachers the opportunity to address them multiple times in the classroom in different ways. Misconceptions are commonplace in the science classroom and often times remain misconceptions forever if not addressed properly.

Initially we planned to study the question "How will the use of station activities affect student misconceptions in the atomic structure unit?" However, when we looked at the data we were able to collect during this unit, we decided to change our question to "What will happen if we try to use station activities to address student misconceptions in atomic structure?" We made this adjustment because we thought to answer the first question thoroughly and conclude that the intervention of station activities affected student misconceptions we would need pre and post tests and a control group. We were not able to do that in this time period but it would be a possible second stage for this action research.

\section{Future Study}

We found this project to be a good initial investigation that could lead to future research into misconceptions in high school chemistry. If we continued with this second stage, we could develop longer, more detailed, pre-tests for each class based on the ones 
given by Claudia in this unit. This would require us to motivate the students to take the pretest more seriously and to answer the pretest items more completely. Then, we would give the same or very similar items as a post test and compare student scores. The disadvantage of this design would be that it is difficult to determine the misconceptions that cause students to answer pre or post test items incorrectly.

Another possibility we considered would be to try two different interventions to address student misconceptions. For example, one class could use the station activities we used this time. Another class could complete a worksheet or book questions addressing the same topic. This would allow us to have a control group and to compare these two interventions to see whether the station activity was more effective. The disadvantage in this case is that we think all of the strategies we use currently such as stations, labs, warm-ups, worksheets and manipulatives are beneficial to students and we don't want to omit these for any group of our students.

Instead of using the control group design we would prioritize an investigation design that could be more easily integrated with our teaching practice. We would like to continue our investigation of misconceptions by taking a closer look at the type of misconceptions our students have. We would not focus only on station activities but instead look at the impact of all of our teaching strategies during a unit. We would also like to track the conceptual development of individual students. In this investigation we observed that some of the students have misconceptions that they have developed prior to the class and some misconceptions are developed during the class. In other cases, the 
student does not have a misconception, but rather an incomplete recall of a topic. We could categorize these errors and develop a checklist that we would use with students as we observe them and assess their work. This would help us understand which misconceptions are most prevalent and to more rigorously track which students have these misconceptions. Kari would like to try a keeping a chart of all of her students with common errors listed. When she observes a common error, she would check this box by the student's name. For example, she has observed that students think that neutrons make atoms electrically neutral. So, any time she hears or observes a student making this error she will note it in her chart. With this data, she would be able to see which students corrected this misconception by the end of the unit as shown on the unit exam. We would also like to increase our focus in our readings and study design on which strategies are most helpful for changing students' particular misconceptions. 


\section{Chapter 2}

\section{Michigan Teacher Excellence Program Personal Experience and Impact}

\section{Introduction}

Our way down the beach was blocked by dozens of fallen trees. We could climb up between their wet branches or wade out into Lake Superior. Cold water crept up our shorts as we picked our way across stones polished by the waves. We could have turned back, but we didn't. Somewhere along the bluff ahead was a place where an unconformity was visible. We were a motley band of public school teachers who wanted to see it with our own eyes and touch the gritty line on the ledge where millions of years did not deposit a single grain.

Three years before this, I had never heard of an unconformity and wouldn't have appreciated its significance. I now see beaches, gravel pits, power plants and even other science educators differently due to experiences I had in the Michigan Teacher Excellence Program (MITEP). Some of the changes have been dramatic and I wish a series of before and after snapshots could explain my development. However, snapshots would leave out important parts of the weeks of intensive field based classes, online class work and discussions, and group pedagogy meetings over three years. To me the most significant impact of the program has been the earth science content I have learned. I also have a more thorough understanding of inquiry-based science lessons and an expanded professional network of science educators. Overall, I have improved my effectiveness as a science educator, my knowledge of science education research and my leadership skills. 


\section{Previous Teaching Experiences}

In order to explain MITEP's impact I will describe my previous background. I majored in biology as an undergraduate at Kalamazoo College and earned my certification to teach group science (a certification category that has since changed) based on the biology, physics, and chemistry classes I had taken. Although I had not taken any earth science classes, I was certified to teach all areas of science for seventh through twelfth grades. I had never taken a course in science education. After college I entered the U.S. Peace Corps and trained teachers in environmental education in the Dominican Republic. I returned to the U.S. to teach a group of students just as foreign to me: high school students who were placed in earth science classes because they had flunked biology. They ranged from discouraged learners to sworn enemies of school. In my first two years of teaching, I was assigned physical science, astronomy and earth science classes, all areas outside of my expertise in biology. As I followed the earth science textbook teacher's guide, I struggled to make the content relevant to my students. Most of my students did not consider science relevant to their current or future lives. Many of them had serious issues they were dealing with in their personal lives and were at risk of dropping out. In efforts to engage my students I took them to a park to test water quality and we toured the wastewater treatment plant. However, there were whole units in the textbook I dreaded. Earthquakes and volcanoes? How did those affect students in Kalamazoo, Michigan? Glaciers? That chapter seemed to be to be nothing but arcane 
vocabulary words. Meteorology could impact their lives, but I didn’t know which concepts to prioritize for these struggling students. It was frustrating for me that I lacked the understanding of the content to prioritize the big ideas and connect this content to their lives.

After teaching high school for two years I became a science facilitator at an elementary magnet school with a focus on scientific inquiry. My elementary students were thrilled to study science. To them science was a highlight of their week. This school also had a high at-risk population, with $90 \%$ of students qualified for the federal free and reduced lunch program. In my job as a science facilitator I was the science leader at my school; I developed curriculum, trained elementary teachers, and supported their science teaching. During this time I began to learn about teaching using inquiry and seek out professional development opportunities.

When I entered the MITEP program in $2011 \mathrm{I}$ was at a point in my career where I felt some discouragement, awareness that I had a lot to learn about both content and pedagogy, and concern. I puzzled over questions such as: What science is most relevant to the lives of at-risk urban children? What are the skills and knowledge they need to be scientifically literate citizens? How do my urban students connect with nature? How do I teach most effectively? The MITEP program was designed to develop teacher leaders who are empowered to "...lead their schools and districts through the process of systematically improving science teaching and learning" and I hoped that MITEP would help me with these questions (MITEP, 2009). 


\section{Teaching Practice and Skills}

After my first year of MITEP I was hired at the Kalamazoo Area Mathematics

and Science Center (KAMSC), which supports math and science education in Kalamazoo and St. Joseph counties. I currently work with ninth through twelfth grade students who attend KAMSC to take advanced math and science classes. My position as student advocate was designed to serve unique needs at KAMSC; I work part time and spend most of my time teaching college and career preparation and advising students individually. Although I am not teaching science, most of my students are interested in pursuing science, technology, engineering and mathematics careers so it is an interesting student population for me to support. MITEP has affected my knowledge of science and skills, my current practice in my position at KAMSC and my plans for future practice when I return to classroom science teaching.

\section{Earth Science Content Knowledge}

Due to the Geology of Utah's National Parks, Earth Science Institutes, and online courses I feel confident that I can take big ideas in earth science and illustrate these with specific examples, in some cases using local examples and data. Although the Geology of Utah class was not a part of the MITEP courses, I took this course the summer before I began MITEP once I was accepted into the MITEP and Masters of Science in Applied Science Education program. While many MITEP students took this class in their final summer and it would serve as a great capstone experience, I took it as my first earth science course ever. It was all completely new to me--strike, superposition, stratigraphy - 
the vocabulary and concepts piled up quickly. I sometimes felt in over my head, but due to the hands-on inquiry based methods used by instructors Jackie Huntoon and Chris Wojick, I was highly engaged in answering the questions posed in the class and I find have retained quite a bit from the class. I was able to relate experiences from that class to concepts and observations in the following classes, e.g. comparing the unconformity in Colorado and the Lake Superior bluff and contrasting stream flow in Colorado and Houghton.

The Earth Science Institutes were especially helpful in my understanding of water, energy and mineral resources, particularly in Michigan. Visiting sites such as a natural gas power plant, a Superfund site, mines and wastewater treatment facilities gave me a better understanding of complex issues. For example, in Lansing's coal-fired power plant, a manager explained how federal regulation incentivizes the plant to delay installation of pollution reducing features until they are mandated, even though the plant has already purchased the equipment. This, along with seeing the dusty mountain of coal waiting to be burned, is the type of knowledge one doesn't get from a textbook. The use of resources is extremely important for students to understand in order to be informed citizens and I am eager to share stories and pictures of the places I've visited when I return to the classroom.

The Earth Science Institute' fieldwork was a strength of the MITEP program, but so many site visits were packed into these weeks that we had limited time to discuss the questions each day. As part of the inquiry cycle we needed more time to elaborate and 
apply our knowledge. Some of this occurred through the content of Alex Guth's online classes, but in some cases I felt that I handed in answers to questions (especially in ESI II) and was never given feedback on how complete or correct my ideas were.

Overall I felt the MITEP professional development was thorough and prepared me well to teach earth science or environmental science. Before the program I thought of mineral samples as something to order in a labeled kit from a science supply company. Now I think of the big box of rocks that I chipped out of a copper mine wall and gleaned from tailings piles in the Upper Peninsula. I went from dreading teaching about glaciers to being eager to teach students about local features such as a boulder downtown with glacial grooves and the gravel pit at the Kalamazoo Nature Center that is part of an esker. I don't feel like an expert in any area of earth systems, but I feel that I know enough of the big picture and key concepts to design curriculum and lessons for middle or high school students.

\section{Current Practice}

Although I am not teaching science right now, MITEP has affected my current practice. I advise high school students about career and college preparation and I have a broader knowledge of STEM careers that may be interesting for them. During the MITEP program our guest teachers included a geologist who studies mental modeling, an anthropologist who studies industrialization, a mining specialist who scuba dives in Lake Superior, and an astronomer who educates through social media. These careers are not 
typically on the radar for high school students. I assign a career research paper to ninth, tenth and eleventh grade students in which they must choose a career to investigate and find a person to interview in that field. My knowledge of a wide range of careers helps me to suggest careers to investigate that go beyond well known job titles such as doctor and engineer. I encourage students to learn more about STEM careers through experiences like the National Summer Transportation Institute at Michigan Tech and Earth Camp, a camp encouraging exploration of careers in earth science at the University of Michigan. I also organized a field trip to take a group of my students to Grand Valley State University to see astrophysicist Neil DeGrasse Tyson speak. This was motivated by seeing a video of Tyson that Mark Klawiter shared during a pedagogy day. To me the best part of this event was my students seeing the field house packed, not for a sports event but to hear a scientist talk about the nature of science.

Additionally, last year I was hired by the Kalamazoo Nature Center to design a course about natural resource careers for the Kalamazoo Regional Service Agency's Education for Employment program, a program open to tenth through twelfth graders in our region. In the curriculum I was able to use some of the content and skills I learned in MITEP including soil profiling, water quality testing, GPS mapping, and inquiry based lessons. I found my GPS experience to be especially helpful, as this is a skill that high school students can be introduced to that is important in environmental fields. I continue to serve on the advisory board for this course. I also continue my involvement with Earthcaching through corresponding with people who visit my Houghton Earthcache site and reply to the science question posed there. 


\section{Future Practice}

I plan to eventually return to science teaching and there are several lessons from MITEP that I will implement. I will push students to understand where their resources come from and how they can analyze costs and benefits of their extraction and use. I plan to use inquiry in my lessons as much as possible. My students will analyze data, whenever possible using real data. Many of our activities in MITEP integrated math, and although these were sometimes the more frustrating assignments, I think it is important for students to see how math and science are integrated. I plan to use citizen science projects because these are highly engaging and break down the myth that only certain experts can participate in science. Alex Guth's class was a model for using both data analysis and citizen science. I also plan to continue using place-based education. This has always been an interest of mine but I now know of more local resources such as the Michigan Geological Repository for Research and Education.

\section{Knowledge of Science Education}

The STEM learning materials class, lesson study, pedagogy days and development of model "7 E" lessons all helped me develop my understanding of inquiry based science lessons. I was familiar with inquiry before MITEP and taught at an elementary magnet school where scientific inquiry was a focus, but our discussions and readings helped me deepen my understanding. One resource I found very helpful was Inquiry and the National Science Education Standards: A guide for teaching and learning. I often referred to the table showing how each essential feature of classroom 
inquiry can occur on a continuum from less direction from the teacher or material to more (2000, p. 29). Another article we discussed during our pedagogy days that I found useful was "Rethinking Laboratories: Tools for converting cookbook labs into inquiry" because many of the lessons in our curriculum materials are based on traditional approaches that do not engage students in inquiry (Volkman 2003). This article offers practical tools that we used in our lesson study. I found Eisenkraft's article "Expanding the 5E Model" useful because it emphasizes phases of the learning cycle that can help teachers to plan and evaluate successful inquiry lessons and students to transfer learning (2003).

I like the idea of the teacher as coach when planning inquiry lessons. The coach designs the learning experiences (like a sports coach planning sequential workouts) but the team has to do the work. The teacher is sometimes talking and often observing, questioning and listening. The teacher may not talk as much in this role but she is very active. For example, if I am not careful I can find myself giving students the message "yes, your explanations are correct because they match common scientific knowledge" or "no, you have made a mistake gathering evidence or forming an explanation... you haven't drawn the right conclusions that I wanted you to." I want my students to focus on the process and the use of evidence but I also want them to come to the "right answer." Sometimes this involves designing a follow-up activity or investigation. Therefore, I have to be strategic and reflective in my planning and actions in the classroom.

When I designed the curriculum for the Kalamazoo Nature Center I used curriculum design and assessment techniques that we discussed in Kedmon Hungwe's 
STEM learning materials class and used backward curriculum design and created performance assessments for each unit. My hope was that, by the end of the year, the students would be able to look at many artifacts from their performance assessments in a portfolio and have a sense of the skills they learned in the class rather than having just a score or test results that put an emphasis on the teacher's evaluation of the student. Traditional assessments such as multiple choice and short answer tests are not sufficient for assessing inquiry based education. While these traditional assessments are sometimes appropriate, they tend to focus on recall of facts and vocabulary rather than in-depth reasoning and application of concepts. In the constructivist approach, the focus is on what students already know and on the context of the learning. Thus, assessment has to be integrated into the learning process so that we understand student's conceptual understanding before and during instruction. The most effective assessment systems include a variety of instruments. For example, a science unit might include laboratory performance tasks, a lab report, a multiple choice exam and a portfolio. Performancebased assessments are necessary to assess students' scientific inquiry skills.

I also found it helpful to have time to delve into the Next Generation Science Standards (NGSS) in our STEM materials class and while designing the lesson we presented at Michigan Science Teachers Association (MSTA) conference. I think the NGSS advances inquiry based learning by integrating these practices into performance expectations. Writing standards as performance expectations helps teachers to make the important shift from a vaguer "students should know this" to a more specific "students 
who demonstrate understanding can do this: ." This should be very helpful to the implementation of inquiry in schools through curriculum development and assessment alignment.

I also think the emphasis towards engineering in the NGSS is positive. People naturally want to solve problems. The general public can be turned off by the image that scientists are supposed to be objective and want knowledge purely for knowledge's sake. It is important to also present science as problem-solving that is caring and helpful. Engineering is the intersection between science and most people's lives. We ask engineering questions such as: How can I improve the fuel economy of my car? How can I build a ramp for a wheelchair user? Questions of this type are relevant and engaging to us. The NGSS explains differences and similarities between science and engineering for each of the eight practices. This is a realistic and helpful addition to the standards. This is also helpful to me because I work with students who are interested in engineering and it helps me to understand the field.

\section{Knowledge of Science Education Research}

In Dr. Hungwe's action research course I learned about collegial inquiry and professional learning communities. I was surprised to learn how many types of research could fit under these umbrellas. I found it valuable to learn the emphasis on carefully developing a rationale, criteria for success and high quality questions before proceeding with research. I worked with two other teachers to research the use of learning stations in the chemistry classroom. This was a good experience for me because I was able to 
observe in a colleague's classroom and collaborate with other teachers. The downside was that this was not research that would affect my current practice. I also began an individual action research project focused on my practice. In this study I investigated the question: How does my role in career education affect student understanding of STEM careers? In order to answer this question I developed the following questions: Do students perceive their courses at KAMSC as relevant to their future career? Do students know about a wide range of careers beyond the popular job titles of doctor and engineer? Do students complete our program with a desire to pursue a STEM career? I planned to use a combination of analyzing student writing, surveys and student matriculation reports in this study. While I have not completed this project, the process of developing my research question with Dr. Hungwe as my advisor and reading literature on my topic was very helpful. I examined several tools used to measure student interest in STEM careers and identified the STEM Career Interest Survey (STEM-CIS) as the best tool for me to compare my students to students nationally.

\section{Leadership Abilities}

I have developed my leadership abilities in three significant ways: writing curriculum, presenting at the MSTA conference, and building relationships with science educators. Through developing curriculum for a new course, I had the opportunity to collaborate with KRESA and the Kalamazoo Nature Center, consult on lab and classroom construction for the course site and make a presentation to area guidance counselors. I'm 
comfortable with the process of curriculum design and would like to continue this work at some point.

I presented with a group at the 2012 MSTA conference about using Earthcaches in education. I presented at the 2013 MSTA conference about my inquiry based lesson on the Enbridge oil spill in the Kalamazoo River. After these experiences I feel ready to present again at this conference or another conference. Although I had previously been an MSTA member I had let my membership lapse for ten years. I found it valuable to rejoin MSTA, attend sessions, receive news and feel more connected to other educators and available resources.

The most important impact on my leadership skills is the network of science educators that I now feel part of. Opportunities for collaboration between teachers in the same building are usually limited and collaborating with teachers from other schools, districts and universities is very rare. Before MITEP I knew only one of the teachers in my cohort. I have now spent weeks learning side by side with teachers from Kalamazoo and Jackson. I have worked on a lesson study, classroom observations and action research in two high schools in my district and continue to communicate with these teachers. If I have a question about AP Chemistry, farm education, or how to build a scale model of a solar system I know which teachers to ask. I also have connections with university resources. Heather Petcovic and Carla Koretsky at Western Michigan University are local resources I can use for geosciences. I have also referred my high school students to engineering summer camps at Michigan Tech and to talk to Dr. 
Koretsky about studying science in the Honor's College at Western Michigan University. These personal connections are invaluable.

\section{Conclusion}

MITEP had several strengths that made it highly effective. One was the formation of cohorts that allowed us to work with the same colleagues and develop meaningful relationships over three years. Another strength was the instructors' enthusiasm and carefully planned learning experiences. The passion of instructors such as Bill Rose and Steve Maddox for their specialties was evident. Also evident was the instructors' genuine concern that we as public school teachers be empowered to teach about the earth science issues of our time in our communities. The diverse delivery methods used over an extended time set this program apart from other professional development opportunities. The extensive time we spent in training will have a lasting effect on me and on our district. The paid graduate credit and stipends made it possible for many teachers in our district to participate in the program. It was also helpful that the MITEP program was flexible enough to allow teachers to continue to participate even when our teaching positions changed.

A limitation of MITEP was that I felt we never adequately addressed specific issues that arise when teaching children in poverty. In the Kalamazoo Public Schools $71 \%$ of students qualify for the federal subsidized lunch program (Mack 2013). Grand Rapids and Jackson public school teachers have similar student populations. Risk factors associated with poverty, including homelessness, maltreatment, lead exposure and poor 
prenatal care, can negatively impact students' educational experience (Golub 2014). As teachers we see this every day. Informally, we share stories: a student who stays in a shelter and falls asleep in class, the time the electronic balances were stolen during a lab, students who have never seen a Great Lake and teachers who face burnout. I would have liked to have more constructive conversations about strategies that address the particular needs of our students. Engaging at-risk students and students with other diverse needs is an ongoing challenge and important opportunity for collaboration.

Another area for improvement is in MITEP's goal to have teachers be full partners with university faculty in school reform. The abstract for the MITEP states that ...successful reform depends on the full involvement of teachers who have the skills to lead their colleagues through the process of developing and implementing new instructional approaches. MITEP teacher-leaders and research university faculty are full partners in the process. Teacher-leaders are at the forefront of their schools' and district's efforts to evaluate, design, implement, and test new inquirybased instructional programs. MITEP teacher-leaders help develop common pacing schedules and course assessments. They assist with planning professional development activities and providing ongoing assistance to colleagues (2009).

During the first summer's Earth Systems Institute I felt that the MTU faculty had so much they wished to teach us that they didn't have much time to learn about our input and experiences. There were many years of diverse educational experiences among us in our cohort and I wanted more time to learn from others in the group. I included this 
feedback in my evaluation of the first summer and I felt that this area improved in the subsequent courses and particularly in the pedagogy days. I did feel that the dynamic remained one of instructors (university staff) and students (MITEP teacher participants). While this is typical for professional development for teachers and did not hinder my learning, it would be interesting to see what could move us closer to the goal of "full partners" in the process. Likewise, what could change in our school district to help teachers feel like partners in school and district efforts to design and evaluate new inquiry-based instructional programs? I don’t feel we moved beyond our individual classroom planning to involvement in this type of reform.

Despite these limitations, I remain impressed and grateful for the impact of MITEP on my life. I have made personal connections with teaching colleagues, scientists and university instructors. I have techniques that I am eager to try in the classroom and greater confidence in my teaching and leadership skills. I have a better understanding of the systems that make our planet work and a wealth of experiences and examples that can make those systems come alive for students. 


\section{References}

Barke, H., Hazari, A., \& Yitbarek, S. (2010).Misconceptions in chemistry: Addressing perceptions in chemical education. Berlin: Springer-Verlag.

Committee on Development of an Addendum to the National Science Education Standards on Scientific Inquiry, Center for Science, Mathematics and Engineering Education, National Research Council (2000). Inquiry and the National Science Education Standards: A guide for teaching and learning. Washington, D.C: National Academy Press.

Eisenkraft, A. (2003). Expanding the 5E model. The Science Teacher, 56-59

Golub, J. (2014) Study: poverty risk factors affect school performance. The Daily Pennsylvanian. Retrieved from http://www.thedp.com/article/2014/02/gseeducation-study-poverty-risk-factors.

Horton, C. (2004). Student alternative conceptions in chemistry. Retrieved from http://www.daisley.net/hellevator/misconceptions/misconceptions.pdf

Kier, M.W., Blanchard, M.R., Osborne, J.W., Albert J.L. (2014). The Development of the STEM Career Interest Survey (STEM-CIS). Research in Science Education. 44, 461-481. 
Kind, V. (2004). Beyond appearances: Students' misconceptions about basic chemical ideas 2nd edition. Retrieved from http://www.rsc.org/images/Misconceptions_update_tcm18-188603.pdf

Mack, J. (2013) Nearly half of Kalamazoo-area public schools students participating in subsidized lunch program. Kalamazoo Gazette. Retrieved from http://www.mlive.com/news/kalamazoo/index.ssf/2013/01/44_percent_of_kalamazooarea_p.html.

Michigan teacher excellence program Michigan teacher excellence program (MITEP): A model for improving earth science education nationwide. (n.d.). Retrieved from http://mitep.mspnet.org/.

Miller, G. (n.d.). Misconceptions and issues in quantum theory. Retrieved from http://apcentral.collegeboard.com/apc/members/courses/teachers_corner/155004.h $\underline{\mathrm{tml}}$

Mulford, D. R., \& Robinson, W. R. (2002), An inventory for alternate conceptions among

first semester general chemistry students. Journal of Chemical Education 79 (6), 739-744.

The Next Generation Science Standards (2013) Retrieved April 15, 2014 from http://www.nextgenscience.org/next-generation-science-standards. 
Olenick, R. P. (n.d.). Helping students learn physics better preconceptions and misconceptions. The Comprehensive Conceptual Curriculum for Physics $\left(\mathrm{C}^{3} \mathrm{P}\right)$ Project. Retrieved from http://phys.udallas.edu/C3P/Preconceptions.

Volkmann, M.J., Abell, S.K. (2003). Rethinking laboratories: tools for converting cookbook labs into inquiry. The Science Teacher, 38-41. 